\title{
A Technoeconomic Evaluation of the Potential of Industrial Biotechnology for the Competitive Production of Commodity and Bulk Chemicals
}

Jennifer N. Hennigan ${ }^{\mathrm{a}, 1}$, Philip S. Wagner ${ }^{\mathrm{b}, 1}$, Chris Burk ${ }^{\mathrm{d}}$, John P. Efromson ${ }^{\mathrm{c}}$, Zhixia Ye ${ }^{\mathrm{b}, \mathrm{c}}$, Matthew L. Lipscomb ${ }^{\mathrm{b}}$ and Michael D. Lynch ${ }^{\mathrm{a},+, \mathrm{c}, 2}$

a Department of Chemistry, Duke University Durham, NC.

${ }^{\mathrm{b}}$ DMC Biotechnologies Inc, Boulder, CO.

${ }^{\mathrm{c}}$ Department of Biomedical Engineering, Duke University Durham, NC.

${ }^{\mathrm{d}}$ Burk TechnoEconomics, Reno, NV.

${ }^{1}$ Authors have contributed equally to this work.

${ }^{+}$To whom all correspondence should be addressed.

22Michael.lynch@duke.edu

Fermentation based bioprocesses are routinely developed for higher value products; however, the development of bioprocesses for larger volume chemicals has lagged. While electrification of transportation may enable significant reductions in greenhouse gas emissions in the fuel sector, the production of chemicals, by its very nature, requires a carbon feedstock. The utilization of more sustainable bioprocessing has unique potential in this sector. Despite the startup of several bio-based chemical facilities (Supplemental Materials Table S6), none of these technologies have had break-out success, as measured by the construction of multiple follow on plants. A key barrier to the wide-spread adoption of large scale bio-based processes includes the potential financial return on capital spent on new facilities and, importantly, the comparative financial return for bioprocesses vs. incumbent petrochemical technology. A standard metric of a project's financial return is the internal rate of return or IRR as defined in Figure 1a. Bio-based chemical processes will likely not be extensively commercialized unless they have an IRR that is competitive with petrochemical routes.

To investigate scenarios in which bioprocesses can compete, we performed technoeconomic analyses to estimate the IRR for both fermentation and petrochemical processes for 33 commodity chemicals as outlined in Figure 1 and detailed in the Supplemental Materials. ${ }^{1-3}$ With 
reasonable fermentation metrics (a production rate of $2 \mathrm{~g} / \mathrm{L}-\mathrm{hr}$, titer of $100 \mathrm{~g} / \mathrm{L}$, fermentation yield $>90 \%$ of theoretical, and downstream yield of $95 \%$, sugar pricing at $\$ 0.15 / 1 \mathrm{~b}$ ), bioprocesses for 15 of these chemicals have a positive margin (Figure 1b), but only 8 have a positive IRR, (Figure 1c), and none have an estimated IRR exceeding the incumbent petrochemical process. This is due to fundamental differences in economies of scale for bioprocess and petrochemical based technologies. (Figure 1d) Bioprocessing plants require larger capital investments for the same production capacity and as a result have smaller financial returns. ${ }^{2-4}$ The fermentation metrics and assumptions in Figure 1c correspond to estimated bioprocess capital costs of $\sim \$ 2.50 / \mathrm{kg}$, at the low end of recently reported capital costs for biochemical plants (Figure 1d).

In general, to achieve petrochemical parity, decreases in bioprocess capital costs, or increases in capital efficiency are needed. If bioprocess costs can meet the current cost structure of corn ethanol plants, a group of 26 chemicals have a positive IRR with 17 exceeding new petrochemical facilities (Figure 1f). Production of ethanol from corn is a unique process with very low capital requirements $(\sim \$ 0.50 / \mathrm{kg}$ of annual capacity) and uniquely low operating and capital requirements for purification. Additionally, the use of corn directly (rather than purified sugars) leads to very low feedstock costs, estimated at $\sim \$ 0.04-\$ 0.06 / 1 \mathrm{~b}$ of dextrose.$^{5}$ For most chemicals, capital cost reductions needed to meet corn ethanol cost structures will require significant innovation in bioprocessing technologies as well as cost reductions for downstream purification. Capital costs associated with the downstream purification of a chemical can easily account for over $50 \%$ of the overall capital costs (Supplemental Materials Section A3) . Alternatively, increasing capital efficiency through process intensification has the potential to reduce capital costs, with standard technologies and more standard equipment, but necessitates significant improvements in titers and volumetric production rates, which range from over $4 \mathrm{~g} / \mathrm{L}-\mathrm{hr}$ to over $10 \mathrm{~g} / \mathrm{L}$-hr depending 
on the chemical (Figure 1g-h, Supplemental A8). Volumetric rates are one metric relating the capacity of a facility to the capital spent in construction. These "targets" for new bioprocesses are also moving. For example, newer petrochemical technologies for methyl methacrylate synthesis are expected to have improved returns, which may well redefine performance competitive metrics for any new bioprocess. ${ }^{6}$ To date, much of the field has been focused on improvements in yield. High yields are necessary but not sufficient. Yield is critical for commercial success as it directly impacts production (operating) costs; however, it has less of an impact on capital investment.

Additionally, for new technologies, R\&D investments can dramatically impact potential financial returns on a new process technology, and should be considered when estimating financial returns. While R\&D investments are variable, for new large scale bioprocesses they are not zero, and historically have been over $\$ 75 \mathrm{M}$ and 7 years. ${ }^{7}$ This level of R\&D investment can be on par with the initial capital investment in a new facility. A $75 \mathrm{kta}$ plant with a capital cost of $\$ 1 / \mathrm{kg}$ would cost $\$ 75$ Million USD to build. Historical R\&D costs effectively double this investment (Figure 1a). Significant reductions in $R \& D$ costs are essential to maximize the project level IRR, given a reasonable project lifetime (in this case assumed to be 20 years).

Many R\&D efforts in the production of large volume chemicals are focused on priorities with limited potential to positively impact IRR and the commercial competitiveness with petrochemistry. Novel pathways may not be needed for success in this space, as numerous high yield metabolic pathways have already been described and many have demonstrated feasibility. ${ }^{8-}$ ${ }^{15} \mathrm{R} \& \mathrm{D}$ efforts would be better focused on improving rates of biocatalysis, the intensification of fermentation processes to increase volumetric production rates and titers, and technologies which reduce equipment and capital costs as well as $R \& D$ costs and timelines. If the field of industrial biotechnology hopes to enable the more sustainable production of large volume chemicals that are 
currently produced from petroleum, we need to move past proof of concept, or redefine it, and take on significant new challenges.

\section{Acknowledgements}

We would like to acknowledge the following support: HR0011-14-C- 0075, ONR YIP \# 12043956, and DOE EERE grant \#EE0007563, as well as the NIH CBTE Training Grant \# T32GM008555.

\section{Author Contributions}

J.N. Hennigan and J.P. Efromson collected and compiled the market and pricing data. M.D. Lynch, J.N. Hennigan, P.S. Wagner, and C. Burk performed the process modeling and technoeconomic analyses. J.N. Hennigan, P.S. Wagner, C. Burk, Z. Ye, M.L. Lipscomb and M.D. Lynch prepared the manuscript.

\section{Conflicts of Interest}

P.S. Wagner, Z. Ye, M.L. Lipscomb, and M.D. Lynch have a financial interest in DMC Biotechnologies, Inc. J.N. Hennigan and M.D. Lynch have a financial interest in Roke Biotechnologies, LLC.. C. Burk has a financial interest in Burk TechnoEconomics. 
a)
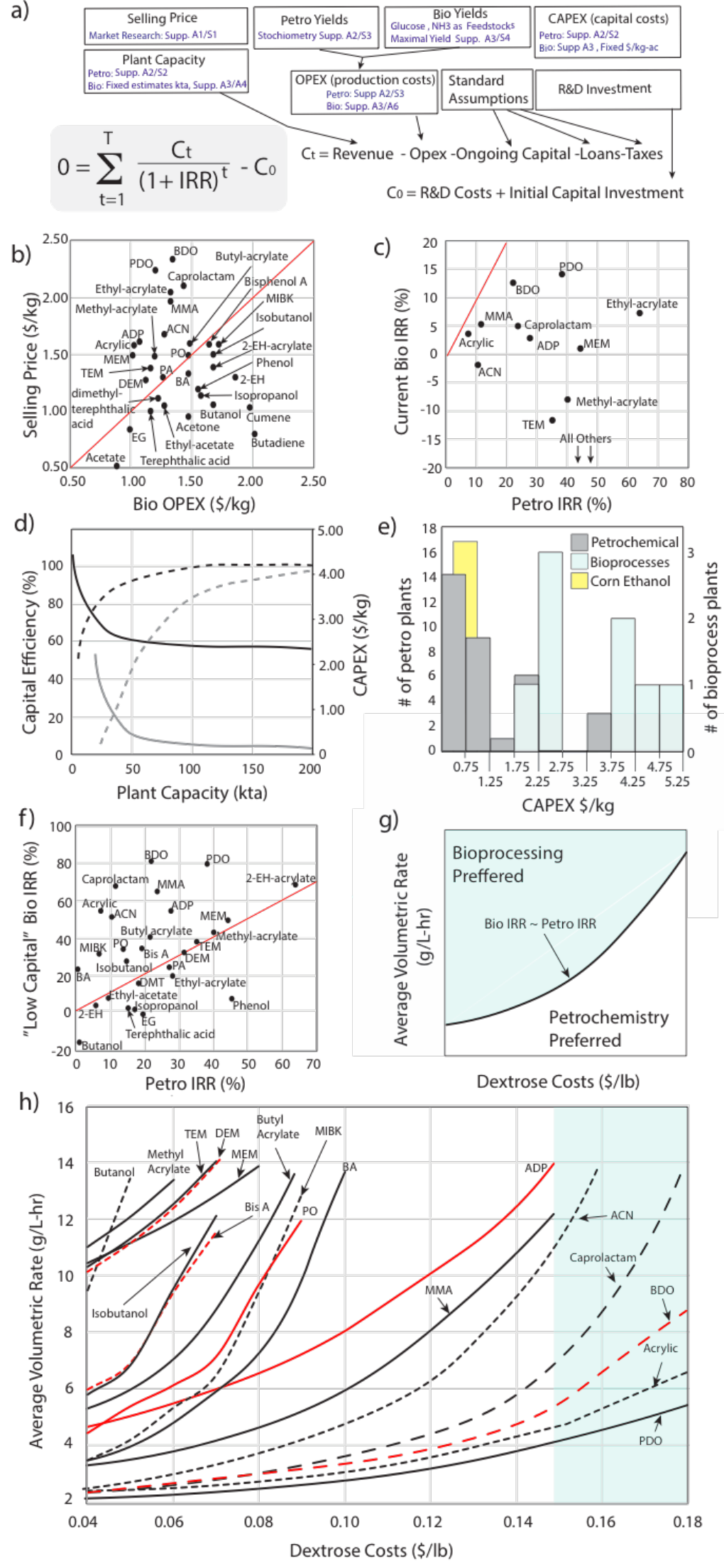
Figure 1: (a) The internal rate of return (IRR) for a given investment is obtained by solving the equation, where $\mathrm{C}_{\mathrm{t}}$ is the net cash flow of year " $t$ ". This is summed over the life of the project(T). Inputs for selling prices, plant capacity, capital and operating costs were used to estimate IRR, according to the details in Supplemental Materials. (b \& c) Bioprocesses assume a rate of $2 \mathrm{~g} / \mathrm{L}-\mathrm{hr}$, titer of $100 \mathrm{~g} / \mathrm{L}$, fermentation yield $>90 \%$ of theoretical, and a downstream yield of $95 \%$, with capital costs of $\sim \$ 2.50 / \mathrm{kg}$ and sugar costs of $\$ 0.15 / \mathrm{lb}$. (b) Estimated production costs (OPEX) for bioprocessing plants vs. 10 year historical pricing for 33 petrochemicals. Above the red line indicates a positive margin. (c) A comparison of the estimated IRR of newly constructed bioprocessing plants (50kta capacity) with newly constructed petrochemical plants. Above the red line would indicate a bioprocess has a higher IRR than the competitive petrochemical process. (d) A comparison of estimated capital costs (solid lines) and capital efficiency (dashed lines) for bioprocess facilities (black lines) and petrochemical facilities (gray lines). Petrochemical data extracted from Hansen et al, 2009. ${ }^{4}$ (e) Estimated capital costs for recent petrochemical, bioprocess and corn ethanol plants. Refer to Supplemental Materials for details. (f) A comparison of the estimated IRR of newly constructed bioprocessing plants if bioprocessing plants can achieve corn ethanol feedstock and capital costs. A rate of $2 \mathrm{~g} / \mathrm{L}-\mathrm{hr}$, titer of $100 \mathrm{~g} / \mathrm{L}$, fermentation yield $>90 \%$ of theoretical, and a downstream yield of $95 \%$, with capital costs of $\$ 0.50 / \mathrm{kg}$ and feedstock costs of $\$ 0.04 / \mathrm{lb}$. (g) A break even analysis for the IRR of petrochemical processes and bioprocesses with cost reduction options including feedstock cost reduction (X-axis) and process intensification (increased volumetric rates, Y-axis). The contour represents equivalence, with regions above the line indicating combinations of process performance and feedstock costs leading to a preferred IRR for a new bioprocess. (h) a break even analysis as described in (g) for a set of 15 chemicals. In this case the fermentation time is held constant at $50 \mathrm{hrs}$, so titers scale with volumetric rates. For example a rate of $4 \mathrm{~g} / \mathrm{L}-\mathrm{hr}$ would deliver a titer of $200 \mathrm{~g} / \mathrm{L}$. Line colors and dashes are used for clarity only. The shaded area represents estimated best case pricing for corn syrup based sugar (DE95) $>\$ 0.15 / \mathrm{lb}$ . Abbreviations: acrylonitrile (ACN), adipic acid (ADP), butyl-acetate (BA), 1,4-butanediol (BDO), bisphenol A (Bis A), diethanolamine (DEM), dimethyl-terephthalate (DMT), 2-ethylhexanol (2-EH), monoethanolamine (MEM), methylisobutyl-ketone (MIBK), methyl-methacrylate (MMA), phthalic anhydride (PA), 1,3-propanediol (PDO), ethylene glycol (PG), propylene oxide (PO), triethanolamine (TEM).

\section{References}

1. Lynch, M. D. The Bioprocess TEA Calculator: An online techno-economic analysis tool to evaluate the commercial competitiveness of potential bioprocesses. BioRxiv (2020) doi:10.1101/2020.10.08.331272.

2. Garrett, D. E. Chemical Engineering Economics. (Springer Science \& Business Media, 2012).

3. Towler, G. \& Sinnott, R. Chemical Engineering Design: Principles, Practice and Economics of Plant and Process Design. (Elsevier, 2012).

4. Hansen, H., Huhn, W., Legrand, O., Steiners, D. \& Vahlenkamp, T. CAPEX Excellence: Optimizing Fixed Asset Investments. (John Wiley and Sons, 2009).

5. Kwiatkowski, J. R., McAloon, A. J., Taylor, F. \& Johnston, D. B. Modeling the process and costs of fuel ethanol production by the corn dry-grind process. Ind. Crops Prod. 23, 288-296 (2006).

6. Lebeau, J., Efromson, J. P. \& Lynch, M. D. A Review of the Biotechnological Production of Methacrylic Acid. Frontiers in Bioengineering and Biotechnology 8, 207 (2020).

7. Allen, J. Andrew Soare,A. and Lynch, J. Synthetic Biology: Applications and Lessons Learned in the Field of Bio-based Materials and Chemicals. (4/17/ 2015). 
8. Zhao, M. et al. Metabolic engineering of Escherichia coli for producing adipic acid through the reverse adipatedegradation pathway. Metab. Eng. 47, 254-262 (2018).

9. Yim, H. et al. Metabolic engineering of Escherichia coli for direct production of 1,4-butanediol. Nat. Chem. Biol. 7, 445-452 (2011).

10. Chae, T. U., Ko, Y.-S., Hwang, K.-S. \& Lee, S. Y. Metabolic engineering of Escherichia coli for the production of four-, five- and six-carbon lactams. Metabolic Engineering vol. 41 82-91 (2017).

11. Burg, J. M., Cooper, C. B., Ye, Z., Reed, B. R. \& Moreb, E. A. Large-scale bioprocess competitiveness: the potential of dynamic metabolic control in two-stage fermentations. Current opinion in Chemical Engineering. 14, 121-136 (2016).

12. Atsumi, S., Hanai, T. \& Liao, J. C. Non-fermentative pathways for synthesis of branched-chain higher alcohols as biofuels. Nature 451, 86-89 (2008).

13. Rodriguez, G. M., Tashiro, Y. \& Atsumi, S. Expanding ester biosynthesis in Escherichia coli. Nat. Chem. Biol. 10, 259-265 (2014).

14. Lynch, M. D., Gill, R. T. \& Lipscomb, T. E. W. Methods for producing 3-hydroxypropionic acid and other products. US Patent 9388419. (2016).

15. Cervin, M. A., Soucaille, P. \& Valle, F. Process for the biological production of 1,3-propanediol with high yield. US Patent 7745184 (2008). 